\title{
Demographic and Socioeconomic Characteristics of COVID-19 Patients Treated in the Emergency Department of a New York City Hospital
}

\author{
Melissa K . James ${ }^{1} \cdot$ Mehwish Kishore $^{2} \cdot$ Shi-Wen Lee ${ }^{3}$ \\ Accepted: 14 October 2020 / Published online: 22 October 2020 \\ ○) Springer Science+Business Media, LLC, part of Springer Nature 2020
}

\begin{abstract}
Demographic and socioeconomic factors can contribute to community spread of COVID-19. The aim of this study is to describe the demographics and socioeconomic factors in relation to geolocation of COVID-19 patients who were discharged from the emergency department (ED) back into the community. This retrospective study was conducted over a 7-week period, at an urban, adult, level 1 trauma center in New York City. Demographics, socioeconomic factors, and geolocation of COVID-19 patients discharged from the ED were extracted from the electronic medical records. Patients were stratified by gender for data analysis. A total of 634 patients were included in the study, 376 (59.3\%) were male and $205(32.3 \%)$ were Hispanic White. The median age of patients was 50 years (IQR: 38, 60, Min:15, Max:96). The unemployment rate in our population was $41.2 \%$ and $75.5 \%$ reported contracting the virus via community spread. ED mortality rate was $11.8 \%$; the majority of which were male $(\mathrm{N}=50,66.7 \%)$ and the median age was 70 years (IQR: 59, 82). There were 9.4\% (95\% CI 2.9-12.4) more Black males and 5.4\% (95\% CI 0.4-10.4) more males who had no insurance coverage compared to females. $26.8 \%$ (95\% CI 14.5-39) more females worked in the healthcare field and 7.1\% (95\% CI 0.3-13.9) more were infected via primary contact compared to males. COVID-19 disproportionately affected minorities and males. Socioeconomic factors should be taken into consideration when preparing strategies for preventing the spread of the virus, especially for individuals who are expected to self-isolate.
\end{abstract}

Keywords Coronavirus $\cdot$ SARS-CoV-2 $\cdot$ Covid- $19 \cdot$ Gender and covid- $19 \cdot$ Community spread

\section{Introduction}

In December 2019, a cluster of acute respiratory illness of unknown cause occurred in the city of Wuhan in Hubei Province, China [1]. This mystery illness is now known as severe acute respiratory syndrome coronavirus-2 (SARSCoV-2) pneumonia or coronavirus disease 19 (COVID-19)

Melissa K . James

mjames3@jhmc.org

Mehwish Kishore

MehwishKishore@mail.rossmed.edu

Shi-Wen Lee

slee@jhmc.org

1 Department of Surgery, Jamaica Hospital Medical Center, 8900 Van Wyck Expressway, Jamaica, NY 11418, USA

2 School of Medicine, Ross University, Portsmouth, Dominica

3 Department of Emergency Medicine, Jamaica Hospital Medical Center, Jamaica, NY, USA
$[2,3]$. What started out as a small cluster in China has now spread throughout the world via international travel and was declared a pandemic by the world health organization (WHO), on March 11th, 2020. To date (10-12-20), over 37 million cases and over 1 million deaths have been reported in 216 countries/regions [2, 4]. Coronaviruses named for their appearance, can cause severe diseases, such as severe acute respiratory syndrome (SARS) and Middle East respiratory syndrome (MERS) [5-10]. The clinical presentation of the novel COVID-19 ranges from mild to critically ill and has an incubation period of $2-14$ days $[2,11]$.

As COVID-19 cases continues to increase globally, research on the clinical presentation and outcomes of hospitalized patients has expanded simultaneously [12-18]. Currently, there is no drug treatment or vaccine for COVID19. Therefore, physicians around the world are forced to be creative in managing and treating this novel virus. At first COVID-19 was considered a respiratory disease but as data emerges it is now considered a multi-organ infection affecting several body systems, with some patients experiencing 
long-term effects after recovery [19, 20]. The first wave of infections in areas such as China, Europe, and New York has provided insight on the symptoms and expected hospital course. In addition, one of the issues highlighted in data from the US was the higher infection rate within minority populations [21-24]. This emphasized the need for socioeconomic determinants of the outbreak in an effort to curb the spread.

The United States of America (USA) is leading the world in the number of COVID-19 cases, with New York State being the initial epicenter of the US [2, 4]. To date (10-1120), New York City (NYC) has a total of 245,128 cases and 19,240 deaths [25]. Our institution is located in the borough of Queens in NYC, which is considered the most racially/ ethnically diverse county in both the USA and the world. The studies published on COVID-19 so far have focused on a single race or minimally diverse populations. This has limited the available data on socioeconomic determinants, which may contribute to the spread and infection rate of COVID-19 in minority populations. Moreover, studies published so far have only provided estimations and projections based on census data and datasets. However, specific data from patients who presented to hospitals is still lacking. Additionally, this study focused on emergency department (ED) discharged patients who were predominantly discharged home to self-isolate. These patients who were released back into the community play an essential role in the spread of the virus. The aim of this study is to describe the demographics, socioeconomic disparities, and geolocation of COVID-19 patients who were discharged from the ED of a New York City hospital.

\section{Methods}

\section{Study Design and Setting}

Over 117,000 patients are treated annually in the ED at our institution. This retrospective study included COVID-19 infected patients who were discharged from the ED, over a 7-week period, at an urban, adult, level 1 trauma center. The aim of this study is to describe the demographics, socioeconomic disparities, and geolocation of confirmed and suspected COVID-19 patients discharged from the ED. This study was approved by our institutional review board; patient consent was not required for this exempt study.

Our hospital currently services over 1.2 million residents in Queens and Eastern Brooklyn in New York City (NYC). Three of the neighborhoods we serve are designated medically underserved areas by the Health Resources and Services Administration [26]. Additionally, data from NYC Department of Health and Mental Hygiene indicates that $\sim 25 \%$ of the residents in our service area are uninsured. A considerable percentage is also foreign born and have a weighted average household income of $\$ 56,836$. Over $52 \%$ of the service area is female, and most of the population identify as racial/ethnic minority residents. The racial/ethnic breakdown of neighborhoods within our primary service area are described in Table 5 [27, 28].

Retrospective review of electronic medical records of COVID-19 patients was performed. Charts were reviewed for reported travel or contact with positive subjects, age, gender, race/ethnicity, primary language, marital status, employment status, and housing type. Additionally, variables such as BMI, insurance type, co-morbidities, transport mode, and ED disposition were also collected when available. As for possible source of exposure, primary spread/ contact was defined as known contact with a confirmed COVID-19 positive individual/s. Community spread was defined as no known contact with COVID-19 positive or sick individuals and unknown source of transmission.

\section{Selection of Participants}

All ED discharged, confirmed and suspected COVID19 patients that presented to the ED during the period of March 14th, 2020 to April 30th, 2020 were included in the study. A list of patients was generated from the daily ED logs based on chief compliant as well as ICD-10 diagnosis. Patients who had more than one visit to the ED were included in the study; data was collected from a subsequent visit if it was not obtained from the first visit. Confirmed COVID-19 cases were defined as those that were confirmed by a positive reverse transcriptase polymerase chain reaction (RT-PCR) assay. Not all suspected cases were confirmed by RT-PCR assays due to limited test kits and restrictions on testing in the early phase of the pandemic. However, these patients were considered positive cases based on clinical triage, chest $\mathrm{x}$-ray/computed tomography, and physician discretion. COVID-19 antibody testing was performed on some patients at later visits.

\section{Data Analysis}

To analyze data GraphPad Prism 6 (GraphPad Software Inc., La Jolla, CA) was used, significant p-values were highlighted in bold in the tables, $\mathrm{p}<0.05$ was considered significant. Patients were stratified by gender for data analysis. Categorical variables are expressed as count $(N)$ and percent (\%) and continuous variables are expressed as median and interquartile range (IQR). For categorical variables, significance testing was done using Fisher's exact test; the difference between proportions was calculated along with a $95 \%$ confidence interval (CI). For continuous variables, the sample was first assessed for normality using the Shapiro-Wilk normality test followed by the Mann-Whitney non-parametric test. The difference between medians was also calculated 
with a corresponding $95 \%$ confidence interval. Line graphs of the number of patients in each zip code for different variables was plotted to show trends in these variables.

\section{Results}

A total of 634 patients were included in the study, 376 (59.3\%) were male and 258 (40.7\%) were female. The median age of patients was 50 years (IQR: 38,60 ); the minimum age was 15 years and the maximum age was 96 years. The most common race/ethnicity was Hispanic White represented by 205 (32.3\%) patients. Most patients $(394,62.1 \%)$ arrived via either private or public transportation (Table 2). The majority of the study population were married $(271,43.2 \%)$, lived in a private house (349, $55 \%$ ), and were unemployed $(261,41.2 \%)$ (Tables 2, 3). Most patients $(479,75.5 \%)$ were infected via community spread, while 155 (24.4\%) patients reported direct contact with known COVID-19 positive individuals (Table 4). Of the study population, 195 (30.7\%) patients were tested for COVID-19 and all tested positive. Most of the study population was discharged home from the ED $(530,83.6 \%)$; however, 75 patients $(11.8 \%$ ) died in the ED. There were 346 (54.6\%) patients who had at least one pre-existing condition and 288 (45.4\%) patients had no pre-existing conditions.
Hypertension (204, 32.2\%) and diabetes (128, 20.2\%) were the most common comorbidities. A third (214, 33.7\%) of the patients were overweight with a BMI in the range of $25-29.9 \mathrm{~kg} / \mathrm{m}^{2}$ and approximately another third (199, $31.4 \%$ ) were obese/morbidly obese with a BMI $>30 \mathrm{~kg} / \mathrm{m}^{2}$ (Table 4).

Studies have suggested that males were disproportionately infected and hospitalized with COVID-19. Therefore, our population was stratified by gender to determine variances between males and females. There were only a few significant differences in demographics and socioeconomic characteristics between male and female patients. There were 9.4\% (CI 2.9-15.9) more Black males compared to Black females and 2.7\% (CI 0.4-5.7) more female Asians compared to males (Table 1). There was also significantly more females who reported being widowed (2.7\%, CI 0.1-5.2). In regards to social factors, 5.4\% (CI 0.4-10.4) more males than females had no insurance coverage $(\mathrm{p}=0.041)$ (Table 2$)$. There were more females who reported working in the healthcare field (26.8\%, CI 14.5-39). There were also 7.9\% (CI 2.8-13.9) more males that worked in construction and $5.5 \%$ (CI 0.9-10.9) more males that worked in the transportation field compared to females (Table 3). As for transmission of the virus, there were $7.1 \%$ (CI $0.3-13.9$ ) more males
Table 1 Demographic factors stratified by gender

\begin{tabular}{|c|c|c|c|c|c|}
\hline Variable & $\begin{array}{l}\text { All patients } \\
\mathrm{n}=634 \\
(\mathrm{~N}, \%)\end{array}$ & $\begin{array}{l}\text { Male } \\
\mathrm{n}=376 \\
(\mathrm{~N}, \%)\end{array}$ & $\begin{array}{l}\text { Female } \\
\mathrm{n}=258 \\
(\mathrm{~N}, \%)\end{array}$ & $\begin{array}{l}\text { Difference of } \\
\text { proportions }(95 \% \\
\text { CI) }\end{array}$ & $P$ value \\
\hline Median age (years) & 50 (IQR: 38, 60) & 51 (IQR: 39, 61) & 48.5 (IQR: 38, 59) & $2.5(-4$ to 1$)$ & 0.209 \\
\hline \multicolumn{6}{|l|}{ Race } \\
\hline White & $31(4.9)$ & $18(4.8)$ & $13(5)$ & $0.2(-3.2$ to 3.7$)$ & 1 \\
\hline Hispanic White & $205(32.3)$ & $114(30.3)$ & $91(35.3)$ & $4.9(-2.5$ to 12.4$)$ & 0.196 \\
\hline Black & $136(21.4)$ & $95(25.3)$ & $41(15.9)$ & $9.4(2.9$ to 15.9$)$ & 0.006 \\
\hline Hispanic Black & $42(6.6)$ & $29(7.7)$ & $13(5)$ & $2.7(-1.3$ to 6.6$)$ & 0.198 \\
\hline Caribbean Black & $35(5.5)$ & $16(4.2)$ & $19(7.4)$ & $3.1(-0.5$ to 6.7$)$ & 0.111 \\
\hline Caribbean Indian & $57(9)$ & $32(8.5)$ & $25(9.7)$ & $1.2(-3.3$ to 5.7$)$ & 0.672 \\
\hline Asian Indian & $78(12.3)$ & $47(12.5)$ & $31(12)$ & $0.5(-4.7$ to 5.7$)$ & 0.902 \\
\hline Asian & $12(1.9)$ & $3(0.8)$ & $9(3.5)$ & $2.7(0.4$ to 5.7$)$ & 0.018 \\
\hline Other & $35(5.5)$ & $20(5.3)$ & $15(5.8)$ & $0.5(-3.1$ to 4.1$)$ & 0.86 \\
\hline Not documented & $3(0.5)$ & $2(0.5)$ & $1(0.4)$ & $0.1(-1.7$ to 1.6$)$ & 1 \\
\hline \multicolumn{6}{|l|}{ Primary language } \\
\hline English & $458(72.2)$ & 277 (73.7) & $181(70.1)$ & $3.5(-3.6$ to 10.6$)$ & 0.367 \\
\hline Spanish & $155(24.4)$ & $85(22.6)$ & $70(27.1)$ & $4.5(-2.3$ to 11.3$)$ & 0.221 \\
\hline Bengali/Sylheti & $8(1.3)$ & $2(0.5)$ & $6(2.3)$ & $1.8(-0.08$ to 4.5$)$ & 0.068 \\
\hline Punjabi & $5(0.8)$ & $5(1.3)$ & $0(0)$ & $1.3(-0.3$ to 3.1$)$ & 0.083 \\
\hline Hindi & $3(0.5)$ & $3(0.8)$ & $0(0)$ & $0.8(-0.8$ to 2.3$)$ & 0.275 \\
\hline Urdu & $2(0.3)$ & $1(0.3)$ & $1(0.4)$ & $0.1(-1.1$ to 1.9$)$ & 1 \\
\hline Mandarin & $1(0.2)$ & $1(0.3)$ & $0(0)$ & $0.3(-1.2$ to 1.5$)$ & 1 \\
\hline Arabic & $2(0.3)$ & $1(0.3)$ & $1(0.4)$ & $0.1(-1.1$ to 1.9$)$ & 1 \\
\hline
\end{tabular}

$P$ values highlighted in bold were considered significant $(\mathrm{p}<0.005)$ 
Table 2 Social factors stratified by gender

\begin{tabular}{|c|c|c|c|c|c|}
\hline Variable & $\begin{array}{l}\text { All patients } \\
\mathrm{n}=634 \\
(\mathrm{~N}, \%)\end{array}$ & $\begin{array}{l}\text { Male } \\
\mathrm{n}=376 \\
(\mathrm{~N}, \%)\end{array}$ & $\begin{array}{l}\text { Female } \\
\mathrm{n}=258 \\
(\mathrm{~N}, \%)\end{array}$ & $\begin{array}{l}\text { Difference of propor- } \\
\text { tions }(95 \% \mathrm{CI})\end{array}$ & $P$ value \\
\hline \multicolumn{6}{|l|}{ Marital status } \\
\hline Single & $271(42.7)$ & $164(43.6)$ & $107(41.5)$ & $2.1(-5.7$ to 9.9$)$ & 0.624 \\
\hline Married & $274(43.2)$ & $160(42.5)$ & $114(44.2)$ & $1.6(-6.2$ to 9.5$)$ & 0.684 \\
\hline Legally separated & $17(2.7)$ & $11(2.9)$ & $6(2.3)$ & $0.6(-1.9$ to 3.2$)$ & 0.804 \\
\hline Divorced & $26(4.1)$ & $16(4.2)$ & $10(3.9)$ & $0.4(-2.8$ to 3.5$)$ & 1 \\
\hline Widowed & $17(2.7)$ & $6(1.6)$ & $11(4.3)$ & 2.7 (0.1 to 5.2$)$ & 0.047 \\
\hline Not documented & $29(4.6)$ & $19(5)$ & $10(3.9)$ & $1.2(-2.1$ to 4.5$)$ & 0.564 \\
\hline \multicolumn{6}{|l|}{ Housing type } \\
\hline Private house & $349(55)$ & $211(56.1)$ & $138(53.5)$ & $2.6(-5.2$ to 10.5$)$ & 0.517 \\
\hline Apartment & $248(39.1)$ & $138(36.7)$ & $110(42.6)$ & $5.9(-1.8$ to 13.7$)$ & 0.137 \\
\hline Group home & $3(0.5)$ & $3(0.8)$ & $0(0)$ & $0.8(-0.8$ to 2.3$)$ & 0.275 \\
\hline Nursing home & $21(3.3)$ & $14(3.7)$ & $7(2.7)$ & $0.9(-1.9$ to 3.8$)$ & 0.652 \\
\hline Shelter & $2(0.3)$ & $2(0.5)$ & $0(0)$ & $0.5(-1.0$ to 1.9$)$ & 0.517 \\
\hline Homeless & $7(1.1)$ & $5(1.3)$ & $2(0.8)$ & $0.5(-1.6$ to 2.4$)$ & 0.707 \\
\hline Not documented & $4(0.6)$ & $3(0.8)$ & $1(0.4)$ & $0.4(-1.4$ to 1.9$)$ & 0.649 \\
\hline \multicolumn{6}{|l|}{ Primary insurance } \\
\hline Commercial & $300(47.3)$ & $169(44.9)$ & $131(50.8)$ & $5.8(-2.1$ to 13.7$)$ & 0.169 \\
\hline Medicaid & $184(29)$ & $110(29.2)$ & $74(28.7)$ & $0.6(-6.6$ to 7.8$)$ & 0.929 \\
\hline Medicare & $78(12.3)$ & $46(12.2)$ & $32(12.4)$ & $0.2(-5$ to 5.4$)$ & 1 \\
\hline No coverage & $72(11.4)$ & $51(13.6)$ & $21(8.1)$ & $5.4(0.4$ to 10.4$)$ & 0.041 \\
\hline \multicolumn{6}{|l|}{ Mode of arrival } \\
\hline EMS & $240(37.8)$ & $147(39.1)$ & $93(36)$ & $3.1(-4.7$ to 10.7$)$ & 0.454 \\
\hline Non-EMS & $394(62.1)$ & $229(60.9)$ & $165(64)$ & $3(-4.6$ to 10.6$)$ & 0.454 \\
\hline
\end{tabular}

$P$ values highlighted in bold were considered significant $(\mathrm{p}<0.005)$ who contracted the virus via community spread, while more females contracted it via primary contact with a known COVID-19 positive person $(\mathrm{p}=0.048)$. There were 6.7\% (CI 0.9-12.6) more females who did not require admission for treatment and were discharged home directly from the ED $(p=0.029)$. Additionally, $6.2 \%$ (CI 2.2-10.2) more males compared to females were current smokers $(\mathrm{p}=0.002)$ (Table 4$)$.

Many studies have used zip code or county level data to make inferences on socioeconomic factors. In this study, socioeconomic factors were assessed at the individual patient level. Demographic and socioeconomic factors were assessed by zip code of patients in our study population. The proportion of each race/ethnicity in our primary service area is shown in Table 5 [27, 28]. Figure 1 shows the number of patients from each zip code who were $\geq 65$ years old, male gender, unemployed, or who had no insurance coverage. Figure 2 shows the number of patients from each zip code who died, tested positive for COVID-19, and who had comorbidities.

\section{Discussion}

Thus far, studies have focused on more severe cases of COVID-19 infection, which have resulted in hospitalization. However, to fully understand the process of transmission and infection, data on all patients that were infected with COVID-19 is needed. In this study, data on confirmed and suspected COVID-19 patients who were discharged from the ED was presented. Due to testing restrictions in the early phase of the pandemic, many of the patients did not meet the criteria for testing $[29,30]$. These patients were considered positive COVID-19 infections based on clinical diagnosis/radiology tests and physician discretion. ED disposition was predominantly home, with mortality and transferred to another facility as other dispositions. Transferred patients met criteria for admission but were transferred due to a lack of bed availability, despite our $100 \%$ increase in bed capacity. Given that they were expected to self-quarantine, patients who were discharged home are a relevant population. Demographic 
Table 3 Economic factors stratified by gender

\begin{tabular}{|c|c|c|c|c|c|}
\hline Variable & $\begin{array}{l}\text { All patients } \\
\mathrm{n}=634 \\
(\mathrm{~N}, \%)\end{array}$ & $\begin{array}{l}\text { Male } \\
\mathrm{n}=376 \\
(\mathrm{~N}, \%)\end{array}$ & $\begin{array}{l}\text { Female } \\
\mathrm{n}=258 \\
(\mathrm{~N}, \%)\end{array}$ & $\begin{array}{l}\text { Difference of proportions } \\
(95 \% \mathrm{CI})\end{array}$ & $\mathrm{P}$ Value \\
\hline \multicolumn{6}{|l|}{ Employment status } \\
\hline Employed (full-time) & $229(36.1)$ & $127(33.8)$ & $102(39.5)$ & $5.8(-1.8$ to 13.4$)$ & 0.153 \\
\hline Employed (part-time) & $20(3.1)$ & $12(3.2)$ & $8(3.1)$ & $0.1(-2.7$ to 2.9$)$ & 1 \\
\hline Not employed & $261(41.2)$ & $156(41.5)$ & $105(40.7)$ & $0.8(-7.0$ to 8.6$)$ & 0.87 \\
\hline Self-employed & $11(1.7)$ & $9(2.4)$ & $2(0.8)$ & $1.6(-0.7$ to 3.8$)$ & 0.214 \\
\hline Retired & $72(11.4)$ & $43(11.4)$ & $29(11.2)$ & $0.2(-4.8$ to 5.2$)$ & 1 \\
\hline Not documented & $41(6.5)$ & $29(7.7)$ & $12(4.6)$ & $3.1(-0.8$ to 6.9$)$ & 0.141 \\
\hline \multicolumn{6}{|l|}{ Employment area $(n=229)$} \\
\hline Healthcare & $76(33.2)$ & $27(21.3)$ & $49(48)$ & $26.8(14.5$ to 39$)$ & $<0.0001$ \\
\hline Retail/sales & $13(5.7)$ & $10(7.9)$ & $3(2.9)$ & $5(-1.5$ to 11.2$)$ & 0.152 \\
\hline Restaurant/catering/grocery & $17(7.4)$ & $10(7.9)$ & $7(6.9)$ & $1(-5.8$ to 7.8$)$ & 0.806 \\
\hline Construction/real estate & $10(4.4)$ & $10(7.9)$ & $0(0)$ & $7.9(2.8$ to 13.9$)$ & 0.003 \\
\hline Law enforcement/fire dept./prison & $10(4.4)$ & $6(4.7)$ & $4(3.9)$ & $0.8(-5.5$ to 6.5$)$ & 1 \\
\hline School/daycare & $5(2.2)$ & $2(1.6)$ & $3(2.9)$ & $1.4(-3.1$ to 7.5$)$ & 0.658 \\
\hline Airline/airport & $9(3.9)$ & $7(5.5)$ & $2(2)$ & $3.5(-2.1$ to 9.2$)$ & 0.305 \\
\hline Manufacturing/warehouse & $8(3.5)$ & $6(4.7)$ & $2(2)$ & $2.8(-2.8$ to 8.1$)$ & 0.304 \\
\hline Transportation & $7(3.1)$ & $7(5.5)$ & $0(0)$ & $5.5(0.9$ to 10.9$)$ & 0.018 \\
\hline Service company & $31(13.5)$ & $20(15.7)$ & $11(10.8)$ & $4.9(-4$ to 13.9$)$ & 0.333 \\
\hline Non-profit organization & $4(1.7)$ & $1(0.8)$ & $3(2.9)$ & $2.1(-1.9$ to 7.5$)$ & 0.326 \\
\hline Government/city agency & $8(3.5)$ & $5(3.9)$ & $3(2.9)$ & $1(-4.8$ to 6.3$)$ & 0.735 \\
\hline Not documented & $31(13.5)$ & $16(12.6)$ & $15(14.7)$ & $2.1(-6.8$ to 11$)$ & 0.7 \\
\hline
\end{tabular}

$P$ values highlighted in bold were considered significant $(\mathrm{p}<0.005)$

and socioeconomic factors may play a significant role in whether these patients adhere to self-isolation mandates.

As expected, most of the patients who presented with COVID-19 symptoms were from our primary service area. At least three of the neighborhoods we serve are designated medically underserved areas by the Health Resources and Services Administration. This is based on the ratio of primary medical care physicians per 1,000 population, infant mortality rate, percentage of the population with incomes below the poverty level, and percentage of the population age 65 or older $[26,28]$. This is consistent with data that suggests that poorer, underserved communities were predominantly affected by the pandemic. The poverty rate in the zip codes with the highest numbers of patients ranged from $20-30 \%$, which is above the rate for NYC. In 2019, the unemployment rate in these neighborhoods ranged from $10-30 \%$, with one neighborhood having a rate $44 \%$ higher than the rate for NYC. Similarly, the uninsured rate ranged from 10 to $15.7 \%$, with $7-10.9 \%$ reporting going without needed medical care due to a lack of insurance coverage. Furthermore, many of the patients in our population live in overcrowded housing with greater than one person per room $[27,28]$.
Hispanic Whites, Blacks, and Asian Indians were the predominant races/ethnicities in our population, which is representative of our primary service area. Over forty percent of the study population was unemployed, which may have contributed to food insecurity in these high-need, lowincome communities. In NYC, many food banks struggled to meet the increased need and were forced to close. During the peak of the pandemic, many financially and medically vulnerable patients ventured out to wait in crowds and long lines for assistance. It will be interesting to determine if food insecurity played a role in the spread of the virus. Only about a third of our patients were tested for COVID19 , which demonstrates the lack of testing in minority populations in the early phase of the pandemic. When it was determined at the state level that minorities were being disproportionately affected by COVID-19, testing centers were increased in minority neighborhoods. Providing access to testing and healthcare for underserved communities, which typically have a higher rate of uninsured individuals and undocumented immigrants, should help control the spread of COVID-19.

Most studies have demonstrated that males were more likely to be hospitalized and die from COVID-19. Despite 
Table 4 Transmission, testing, ED disposition and comorbidities stratified by gender

\begin{tabular}{|c|c|c|c|c|c|}
\hline Variable & $\begin{array}{l}\text { All Patients } \\
\mathrm{n}=634 \\
(\mathrm{~N}, \%)\end{array}$ & $\begin{array}{l}\text { Male } \\
\mathrm{n}=376 \\
(\mathrm{~N}, \%)\end{array}$ & $\begin{array}{l}\text { Female } \\
\mathrm{n}=258 \\
(\mathrm{~N}, \%)\end{array}$ & $\begin{array}{l}\text { Difference of } \\
\text { proportions }(95 \% \\
\text { CI) }\end{array}$ & $P$ value \\
\hline \multicolumn{6}{|l|}{ Possible source of infection } \\
\hline Primary contact & $155(24.4)$ & $81(21.5)$ & $74(28.7)$ & $7.1(0.3$ to 13.9$)$ & 0.048 \\
\hline Community spread & $479(75.5)$ & $295(78.5)$ & $184(71.3)$ & $7.1(0.3$ to 13.9$)$ & 0.048 \\
\hline Work related & $60(9.5)$ & $29(7.7)$ & $31(12)$ & $4.3(-0.3$ to 8.9$)$ & 0.074 \\
\hline Travel related & $4(0.6)$ & $0(0)$ & $4(1.5)$ & $1.5(0.2$ to 3.9$)$ & $\mathbf{0 . 0 2 7}$ \\
\hline COVID-19 test done & $195(30.7)$ & $126(33.5)$ & $69(26.7)$ & $6.8(-0.5$ to 14.1$)$ & 0.08 \\
\hline IgG COVID -19 antibody test done* & $15(2.4)$ & $6(1.6)$ & $9(3.5)$ & $1.9(-0.5$ to 4.3$)$ & 0.182 \\
\hline \multicolumn{6}{|l|}{ ED disposition } \\
\hline Home & $530(83.6)$ & $304(80.8)$ & $226(87.6)$ & $6.7(0.9$ to 12.6$)$ & 0.029 \\
\hline Transferred to other facility & $29(4.6)$ & $22(5.8)$ & $7(2.7)$ & $3.1(-0.2$ to 6.4$)$ & 0.081 \\
\hline Expired & $75(11.8)$ & $50(13.3)$ & $25(9.7)$ & $3.7(-1.5$ to 8.7$)$ & 0.21 \\
\hline$>1$ ED visit & $93(14.7)$ & $57(15.2)$ & $36(13.9)$ & $1.2(-4.4$ to 6.8$)$ & 0.732 \\
\hline Admitted after return to the ED & $25(3.9)$ & $18(4.8)$ & $7(2.7)$ & $2.1(-1$ to 5.1$)$ & 0.217 \\
\hline Comorbidities present & $346(54.6)$ & $199(52.9)$ & $147(57)$ & $4(-3.8$ to 11.9$)$ & 0.331 \\
\hline \multicolumn{6}{|l|}{ Smoking history } \\
\hline Current smoker & $43(6.8)$ & $35(9.3)$ & $8(3.1)$ & $6.2(2.2$ to 10.2$)$ & 0.002 \\
\hline Former smoker & $35(5.5)$ & $23(6.1)$ & $12(4.6)$ & $1.5(-2.1$ to 5.1$)$ & 0.482 \\
\hline \multicolumn{6}{|l|}{ BMI $\left(\mathrm{kg} / \mathrm{m}^{2}\right)$} \\
\hline$<18.5$ & $9(1.4)$ & $5(1.3)$ & $4(1.5)$ & $0.2(-1.8$ to 2.7$)$ & 1 \\
\hline $18.5-24.9$ & $147(23.2)$ & $86(22.9)$ & $61(23.6)$ & $0.8(-5.9$ to 7.5$)$ & 0.848 \\
\hline $25-29.9$ & $214(33.7)$ & $130(34.6)$ & $84(32.6)$ & $7.2(-0.7$ to 15.1$)$ & 0.084 \\
\hline$>30.0$ & $199(31.4)$ & $113(30)$ & $86(33.3)$ & $3.3(-4.1$ to 10.6$)$ & 0.385 \\
\hline Not documented & $65(10.2)$ & $42(11.2)$ & $23(8.9)$ & $2.2(-2.5$ to 7.1$)$ & 0.424 \\
\hline
\end{tabular}

*Antibody testing was done at subsequent ED visits

$P$ values highlighted in bold were considered significant $(p<0.005)$
Table 5 Distribution of race/ethnicity by community districts in our primary service area

\begin{tabular}{lllll}
\hline \multirow{2}{*}{$\begin{array}{l}\text { Community } \\
\text { district }\end{array}$} & \multicolumn{4}{l}{ Race/ethnicity } \\
\cline { 2 - 5 } & White (\%) & Black (\%) & Hispanic (\%) & Asian (\%) \\
\hline 9 and 10 & 18.7 & 12.4 & 33.5 & 23.1 \\
8 and 12 & 6.2 & 50 & 19.5 & 17.4 \\
4 and 5 & 2.2 & 49.4 & 38.3 & 6.3 \\
\hline
\end{tabular}

Community Districts 9 and 10 consists of the following zip codes: $11,414,11,415,11,416,11,417,11,418,11,419,11,420,11,421$. Community Districts 8 and 12 consists of the following zip codes: $11,412,11,423,11,432,11,433,11,434,11,435,11,436$. Community Districts 4 and 5 consists of the following zip codes: 11,207, 11,208. Data obtained from New York City Health Profiles, New York City Department of Health

including mainly patients who were discharged home; our population also consisted of more males than females. However, our population was more racially diverse compared to other studies. The higher rate of mortality in our male population suggests that males were more severely infected compared to females. In addition, more males were transferred

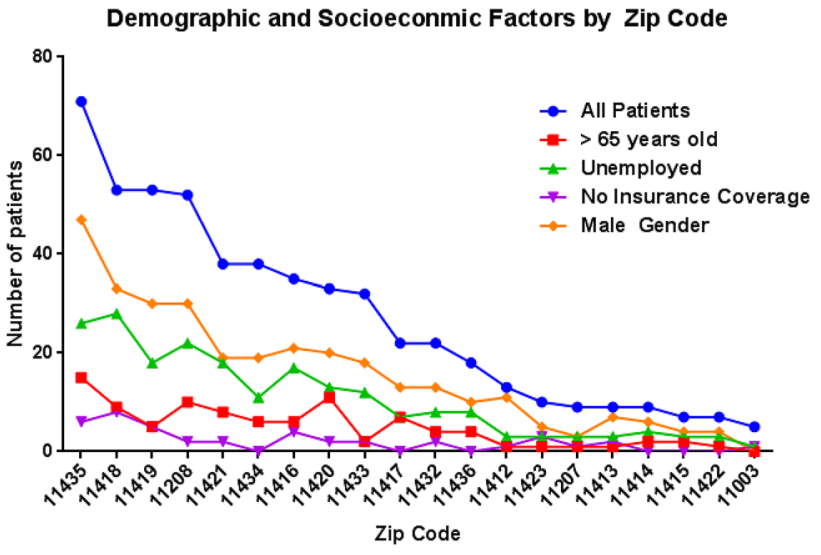

Fig. 1 Demographic and Socioeconomic Factors by zip codes. The number of patients for each variable was plotted by zip code

to another facility for admission and treatment. Males had a significantly higher rate of heart disease and more males were current smokers compared to females, which may have contributed to illness severity. Moreover, demographic and socioeconomic factors may have also contributed to how 


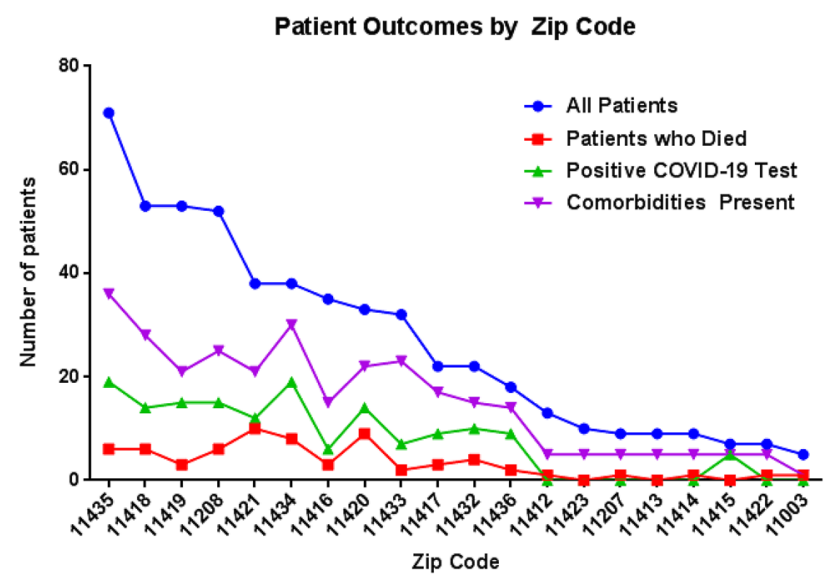

Fig. 2 Patient outcomes by zip codes. The number of patients for each variable was plotted by zip code

males and females experienced the disease. There were more Black males and males with no insurance coverage compared to females, in our population. Racial disparities and lack of access to healthcare have long been factors that contribute to health outcomes. Not to mention, women tend to be primary caregivers and are more likely to seek preventative healthcare compared to men. There were also differences in the area of employment among males and females. However, both worked in areas that required direct interactions with others. This should be taken into consideration in order to design targeted strategies to combat the spread.

Roughly twelve percent of our population died in the ED. Most patients presented too late to allow for a favorable outcome, many arrived in cardiac arrest or coded shortly after arrival. A smaller number of patients expired while being boarded in the ED. In accordance with other studies, elderly patients and predominantly males died from COVID19. Overall, non-survivors had a higher rate of pre-existing conditions compared to survivors, confirming that underlying medical conditions increase the risk of mortality. From the early onset of the pandemic, it was suggested that individuals with pre-existing conditions were more vulnerable to severe illness and mortality. In our population, fifty five percent of the patients had at least one pre-existing condition. Similarly, the majority of our population was also overweight or obese/morbidly obese, which is another risk factor for severe illness and mortality.

Community spread was the primary source of exposure to the virus in our study population. Studies have shown that strategies to identify residents with positive symptoms have been insufficient as the infectivity of asymptomatic carriers is the same as symptomatic carriers [31]. Therefore, the need for social distancing and wearing a face mask when outside is crucial to limiting the spread of the virus. Hospitalized patients have been the main focus during the pandemic; however patients who are discharged home because they do not require admission to the hospital for treatment also deserve attention. These patients are known carriers and their behavior directly affects the spread of the virus. Therefore, strategies to track and ensure that these individuals self-isolate is critical. Contact tracing began late in NYC, after the curve was flattened. Early identification and follow-up with positive cases released back into the community is needed to avoid unnecessary spread. Social and economic disparities can have a direct influence on whether this population transmits the virus to others. Resources that permit social distancing and isolation during the recovery period should be provided to patients who do not have the means to effectively and independently accomplish self-quarantine.

There were some limitations to this retrospective study. This study was limited to a specific geographic region and a single trauma center therefore, the results may not be generalizable or applicable to other centers. It is possible that patients were missed during the inclusion/selection process, which limited the sample size. Sample size was also limited by the study time frame. Not all patients were confirmed COVID-19 positive via RT-PCR. The low availability of test kits and restrictions of testing during the onset of the outbreak prevented widespread testing. Due to the retrospective design of the study, only data recorded in the medical charts were available. Information such as number of people per household, household income, and education level were not collected for ED discharged patients. Additionally, descriptive statistics were not adjusted for potential cofounders.

In conclusion, we presented data on ED discharged COVID-19 patients from a diverse population and demonstrated that there was some variability between male and female patients. Overall, it appeared that males were more severely ill compared to females based on clinical presentation and mortality rate. Similar to other studies, we showed pre-existing conditions and age played a role in mortality. Patients who are not admitted to the hospital and are discharged home from the ED play a crucial role in curbing the spread of COVID-19. These individuals can negatively impact the infection rate of COVID-19 if they do not either voluntarily or involuntarily adhere to self-isolation orders. Factors such as overcrowded housing, lack of food, and the necessity to continue working may prohibit individuals in poor, underserved communities from self-isolation and social distancing. Strategies to negate demographic and socioeconomic disparities should be taken into consideration at the state and federal level in the fight against COVID-19.

Funding This research did not receive any specific grant from funding agencies in the public, commercial, or not-for-profit sectors. 


\section{Compliance with Ethical Standards}

Conflict of interest All authors declare no conflicts of interest and have no financial ties to disclose.

\section{References}

1. Zhu, N., Zhang, D., Wang, W., Li, X., Yang, B., Song, J., et al. (2020). A novel coronavirus from patients with pneumonia in China, 2019. NEJM, 382(8), 727-733.

2. World Health Organization. (2020). Coronavirus (COVID-19) pandemic. https://www.who.int/emergencies/diseases/novel-coron avirus-2019.

3. Gorbalenya, A. E., Baker, S. C., Baric, R. S., de Groot, R. J., Drosten, C., Gulyaeva, A. A., et al. (2020). The species severe acute respiratory syndrome-related coronavirus: Classifying 2019$\mathrm{nCoV}$ and naming it SARS-CoV-2. Nature Microbiology, 5(4), 536-544.

4. Center for Systems Science at John Hopkins University. (2020). COVID-19 dashboard. https://gisanddata.maps.arcgis.com/apps/ opsdashboard/index.html\#/bda7594740fd40299423467b48e9ec f6.

5. Li, F. (2016). Structure, function, and evolution of coronavirus spike proteins. Annual Review of Virology, 3(1), 237-261.

6. Drosten, C., Gunther, S., Preiser, W., van der Werf, S., Brodt, H. R., Becker, S., et al. (2003). Identification of a novel coronavirus in patients with severe acute respiratory syndrome. NEJM, 348(20), 1967-1976.

7. Ksiazek, T. G., Erdman, D., Goldsmith, C. S., Zaki, S. R., Peret, T., Emery, S. T., et al. (2003). A novel coronavirus associated with severe acute respiratory syndrome. NEJM, 348(20), 1953-1966.

8. Zaki, A. M., van Boheemen, S., Bestebroer, T. M., Osterhaus, A. D., \& Fouchier, R. A. (2012). Isolation of a novel coronavirus from a man with pneumonia in Saudi Arabia. NEJM, 367(19), 1814-1820.

9. Peiris, J. S., Lai, S. T., Poon, L. L., Guan, Y., Yam, L. Y., Lim, W., et al. (2003). Coronavirus as a possible cause of severe acute respiratory syndrome. The Lancet, 361(9366), 1319-1325.

10. de Groot, R. J., Baker, S. C., Baric, R. S., Brown, C. S., Drosten, C., Enjuanes, L., et al. (2013). Middle East respiratory syndrome coronavirus (MERS-CoV): Announcement of the Coronavirus Study Group. Journal of Virology, 87(14), 7790-7792.

11. Li, Q., Guan, X., Wu, P., Wang, X., Zhou, L., Tong, Y., et al. (2020). Early transmission dynamics in Wuhan, China, of novel coronavirus-infected pneumonia. NEJM, 382(13), 1199-1207.

12. Guan, W. J., Ni, Z. Y., Hu, Y., Liang, W. H., Ou, C. Q., He, J. X., et al. (2020). Clinical characteristics of coronavirus disease 2019 in China. NEJM, 382(18), 1708-1720.

13. Wang, D., Hu, B., Hu, C., Zhu, F., Liu, X., Zhang, J., et al. (2020). Clinical characteristics of 138 hospitalized patients with 2019 novel coronavirus-infected pneumonia in Wuhan, China. JAMA, 323(11), 1061-1069.

14. Yang, X., Yu, Y., Xu, J., Shu, H., Xia, J., Liu, H., et al. (2020). Clinical course and outcomes of critically ill patients with SARSCoV-2 pneumonia in Wuhan, China: A single-centered, retrospective, observational study. Lancet Respir Med, 8(5), 475-481.

15. Li, L. Q., \& Huang, T. (2020). COVID-19 patients' clinical characteristics, discharge rate, and fatality rate of meta-analysis. Journal of Medical Virology, 92(6), 577-583.
16. Grasselli, G., Zangrillo, A., Zanella, A., Antonelli, M., Cabrini, L., Castelli, A., et al. (2020). Baseline characteristics and outcomes of 1591 patients infected with SARS-CoV-2 admitted to ICUs of the Lombardy Region, Italy. JAMA, 23(16), 1574-1581.

17. Arentz, M., Yim, E., Klaff, L., Lokhandwala, S., Riedo, F. X., Chong, M., et al. (2020). Characteristics and outcomes of 21 critically ill patients with COVID-19 in Washington state. JAMA, 323(16), 1612-1614.

18. Richardson, S., Hirsch, J. S., Narasimhan, M., Crawford, J. M., McGinn, T., Davidson, K. W., et al. (2020). Presenting characteristics, comorbidities, and outcomes among 5700 patients hospitalized with COVID-19 in the New York City area. JAMA, 323(20), 2052-2059.

19. Renu, K., Prasanna, P. L., \& Valsala, G. A. (2020). Coronaviruses pathogenesis, comorbidities and multi-organ damage-A review. Life Sciences, 255, 117839.

20. Wadman, M., Couzin-Frankel, J., Kaiser, J., \& Matacic, C. (2020). A rampage through the body. Science, 368(6489), 356-360.

21. Abedi, V., Olulana, O., Avula, V., Chaudhary, D., Khan, A., Shahjouei, S., et al. (2020). Racial, economic, and health inequality and COVID-19 Infection in the United States. J Racial Ethn Health Disparities, 1, 1-11.

22. Dorn, A. V., Cooney, R. E., \& Sabin, M. L. (2020). COVID-19 exacerbating inequalities in the US. The Lancet, 395(10232), $1243-1244$.

23. Azar, K. M. J., Shen, Z., Romanelli, R. J., Lockhart, S. H., Smits, K., Robinson, S., et al. (2020). Disparities in outcomes among COVID-19 patients in a large health care system in California. Health Affairs, 39(7), 1253-1262.

24. Raifman, M. A., \& Raifman, J. R. (2020). Disparities in the population at risk of severe illness from COVID-19 by race/ethnicity and income. American Journal of Preventive Medicine, 59(1), 137-139.

25. New York City Department of Health. (2020). COVID-19: Data. https://www1.nyc.gov/site/doh/covid/covid-19-data.page.

26. Health Resources and Services Administration. Medically Underserved Areas (MUA) Find. https://data.hrsa.gov/tools/short age-area/mua-find.

27. New York City Community Health Profiles. (2018). https://www1. nyc.gov/site/doh/data/data-publications/profiles.page\#qn.

28. Jamaica Hospital Medical Center. (2019). Community health needs assessment. https://jamaicahospital.org/docs/csp/JHMC\%20 2019-2021\%20three-year\%20comprehensive\%20CSP-Web\%20 Version.pdf.

29. New York City Department of Health. (2020). COVID-19 testing criteria. https://www1.nyc.gov/assets/doh/downloads/pdf/han/ alert/2020/covid-19-testing-criteria.pdf.

30. Centers for Disease Control and Prevention. (2020). Update and interim guidance on outbreak of coronavirus disease 2019 (COVID-19). https://emergency.cdc.gov/han/2020/HAN00428. asp.

31. Gao, Z., Xu, Y., Sun, C., Wang, X., Guo, Y., Qiu, S., et al. (2020). A systematic review of asymptomatic infections with COVID-19. Journal of Microbiology, Immunology, and Infection. https://doi. org/10.1016/j.jmii.2020.05.001

Publisher's Note Springer Nature remains neutral with regard to jurisdictional claims in published maps and institutional affiliations. 